\title{
LA JUSTICIA COMUNITARIA: UN ACERCAMIENTO DESDE LA FILOSOFÍA POLÍTICA DUSSELIANA ${ }^{1}$
}

\section{ALICIA HOPKINS MORENO}

RESUMEN: En este artículo pretendemos comprender la dimensión comunitaria de la justicia desde la Filosofía Política dusseliana. Partimos del reconocimiento de una especie de "momento oportuno" para que esta escuela de pensamiento, además de buscar la generación de una teoría crítica propositiva para "otro Estado posible", también reconozca la potencia política de la arquitectónica, la crítica y el momento de la praxis constructiva que subyacen a la forma comunitaria en la política moderna.

PALABRAS CLAVE: Dussel; Filosofia Política; Justicia comunitaria.

ABSTRACT: In this article, we try to understand the community dimension of justice from the Dusselian Political Philosophy. We start from the recognition of a kind of "opportune moment" so that this school of thought, in addition to seeking the generation of a critical theory proposing for "another possible State", also recognizes the political power of architecture, criticism and the moment of the constructive praxis underlying the community form in modern politics.

KEYWORDS: Dussel; Political Philosophy; Community justice.

Hemos construido esta reflexión siguiendo el análisis que la Filosofía Política dusseliana hace del proceso político dividiéndolo en tres configuraciones o momentos: el acontecimiento originario de la Totalidad, un momento abstracto que sirve para elucidar los criterios y principios a partir de los cuales la Totalidad se organiza. Una segunda configuración entendida como crítica, en la que es necesario un nuevo horizonte político desde las propias víctimas de la Totalidad; $y$, por último, un tercero que da cuenta de la construcción positiva de una Totalidad nacida del derrumbamiento de la antigua y basada en los alcances críticos de la segunda configuración ${ }^{3}$.

\footnotetext{
${ }^{1}$ Esta reflexión es parte del resultado de investigación de la autora que culminó con la tesis doctoral titulada Elementos para una filosofía latinoamericana de la justicia comunitária.

${ }^{2}$ Catedrática de la Universidad del Claustro de Sor Juana en la Ciudad de México. Doctora en Estudios Latinoamericanos por la Universidad Nacional Autónoma de México (UNAM). E-mail: hopkinsalicia@hotmail.com.

${ }^{3}$ Para mayor detalle, véase "Las tres configuraciones del proceso político", de Enrique Dussel, texto inédito que ha servido de base para la redacción colectiva del tercer tomo de la Política de la Liberación, ahora en proceso de edición.
} 
Para la Política de la Liberación, el poder está fundado en la voluntad de vida de una comunidad política, entendida ésta en el reconocimiento del Otro como persona y en la responsabilidad por la justicia. Dicha comunidad política podemos $-\mathrm{y}$ así se ha venido haciendo - abordarla de manera abstracta y circunscribiéndola a una territorialidad política que funda su existencia en un nivel macro, nacional.

Aunque no negamos la pertinencia de este camino teórico, que establece, desde la Filosofía Política situada en América Latina, una serie de principios y estrategias para contravenir la fetichización del Estado moderno a partir de un «mandar obedeciendo» y de la configuración del pueblo como el actor mesiánico que se enfrenta a la Totalidad dominadora, sí sostenemos la necesidad de dirigir también la mirada hacia una territorialidad distinta, más micro, más local, en la que se suceden experiencias de profundas implicaciones para la Filosofía Política, ya que las comunidades constituyen, a su vez, otras totalidades y exterioridades que dan cuenta de una dimensión distinta de la liberación, que no deja de ser popular, pero que se juega en un terreno con límites y potencialidades que también necesitan ser pensadas.

Cuando la Política de la Liberación se dedica a comprender el nivel geopolítico latinoamericano que mantiene viva la lucha contra el imperialismo estadounidense y, por supuesto, contra el neoliberalismo, se articula teóricamente a las experiencias que durante la última década marcaron lo que ha considerado una especie de "primavera política" de los pueblos latinoamericanos. Los así llamados "gobiernos progresistas" - como el del Lula en Brasil, Mujica en Uruguay, los Kirchner en Argentina, Evo en Bolivia y Correa en Ecuador nutrieron, en este sentido, la producción teórica en la última década.

Lo que sostenemos aquí es que experiencias como las Rondas Campesinas en el Perú, la construcción de vida comunitaria en la urbe por parte de la Organización Popular Francisco Villa de la Izquierda Independiente (OPFVII), pero también del sistema de justicia de la Coordinadora Regional de Autoridades Comunitarias-Policía Comunitaria de Guerrero (CRACPC) y las distintas formas de autogobierno constituidas por Cherán o las comunidades zapatistas en Chiapas - entre muchas otras - tienen como base vínculos, principios, prácticas y mecanismos de hacer política significativos para pensar la liberación.

El poder de la comunidad también se funda en la voluntad de un vivir cara-a-cara con una proximidad mayor y más compleja que aquella que se da en la sociedad moderna, sobre todo en la urbe. Pero también es un vivir-cara-a-territorio que, en cierta medida, descentra cualquier interpretación antropocéntrica del principio material de la vida. En este sentido, buscaremos abrir algunas líneas — en ningún sentido acabadas — desde la Filosofía Política 
de la Liberación para profundizar en la comprensión teórica de la comunidad desde su propio aparato teórico, ampliando su horizonte interpretativo de la política, y ubicándose - como siempre lo ha sostenido - en la retaguardia, aprendiendo del paso que los pueblos, y en este caso, las comunidades dan en su lucha.

\section{El momento arquitectónico de la justicia. El nivel político institucional de la comunidad}

La pregunta que guía nuestra reflexión es: ¿cómo construimos el marco filosófico de la totalidad comunitaria?, de manera analítica: ¿cómo damos cuenta de la voluntad de vivir del cara-a-cara - que es, también, un cara-a-territorio - que nos permita comprender el sentido originario de la justicia comunitaria, considerando tanto las comunidades originarias o rurales, como el caso de las comunidades urbanas?

En las comunidades, la experiencia del cara-a-cara-territorio está transida de sentido histórico, de interpelación constante a una pertenencia, a un formar parte; de exigencia por el equilibrio que permita el mantenimiento de la vida en común. La justicia, en este sentido, expresaría la voluntad comunitaria como fundamento del orden que se ha dado a sí misma, es decir, como potentia y como potestas, en diferentes esferas y con distintos principios.

\section{Las esferas de la comunidad}

\section{A. Esfera material de la política comunitaria}

En la vida comunitaria, a diferencia de la social, los campos y las esferas no se encuentran separadas de manera tan tajante, hay una articulación, un entrecruzamiento de lo que la mirada moderna, como la nuestra, divide: lo sagrado, lo ecológico, lo productivo, lo cultural, etc. Sin embargo, es justo esta mirada la que nos permite - aunque también, paradójicamente, nos limita — analizar las diferencias sustantivas que guarda con la reproducción de la vida social en el capitalismo, donde lo sagrado, lo ecológico y lo productivo están subordinados a la lógica de explotación y acumulación.

La vida comunitaria de algunos pueblos originarios muestra, por ejemplo, una sacralidad experimentada desde la propia vitalidad del territorio, desde una simbólica comunitaria alimentada y transformada a lo largo de su historia. Pero aun en el caso de comunidades rurales que han perdido dicha sacralidad o, en el de las urbanas, la dimensión de la reproducción de la vida en común supone una esfera ecológica en la que el valor de uso de los bienes naturales y la deliberación colectiva sobre el destino de los mismos obedecen a la lógica de un bienestar común. 
Además, la corporalidad viviente de la comunidad, aunque sin abandonarla, trasciende la metafísica de la alteridad basada en la persona y se manifiesta en la comunidad de vida que, asentada en un territorio, también vivo, busca la reproducción concreta, histórica de una manera comunitaria en la que la vida se organiza. El rostro del Otro es el rostro colectivo de la comunidad que organiza su voluntad de vivir. Cuando las y los zapatistas venden café o ganado que son propiedad común, muestran de qué manera lo que la comunidad produce como excedente cumple la función de sostener, facilitar y mantener la reproducción en conjunto de las familias que la constituyen, sobre todo en los casos en lo que se necesita del apoyo económico para procurar la salud de un enfermo, la manutención de una viuda o de los huérfanos, la organización de sus fiestas sagradas, sus acciones políticas o la construcción de infraestructura destinada a albergar sus instituciones. La cultura comunitaria basada en prácticas históricas y en núcleos simbólicos que le dan identidad y sentido de existencia constituye un modo de ser de la comunidad que se expresa en sus rituales, en sus celebraciones, en los propios vínculos con el territorio y en su institucionalidad ${ }^{4}$.

\section{B. Esfera de factibilidad sistémico-institucional de la comunidad}

La comunidad es una Totalidad que está en continuo despliegue entre su exterioridad frente a la Totalidad de la Modernidad y su Totalidad como construcción, desde dicha exterioridad, de otro sistema, que genera, a su vez, nuevas exterioridades. De ahí su riqueza como experiencia política que la Filosofía, incluyendo la de la Liberación, no deberían soslayar. Las comunidades se dan a sí mismas sus instituciones y lo hacen del tal modo que logran preservarlas no sólo en el tiempo, sino como posibilidad fáctica de la reproducción de la vida humana en un territorio. A diferencia de la sociedad, éstas no se conforman por el paso de una "sociedad civil" a una "sociedad política". En la comunidad, la institución antecede siempre, no hay un antes de la comunidad, sino que es, en sí misma, política. En el sentido que no hay un antes que sería el sujeto individual, como origen de lo político, sino que la propia comunidad se antecede a sí misma en la historia — sobre todo en los casos no urbanos —, constituida por un modo de reproducir la vida, una identidad y una historia propia.

En todo caso, pensaríamos que la "sociedad civil" procede de la ruptura de las formas comunitarias que, desintegradas, expulsaron sus miembros a las ciudades. Y, entonces, quizás deberíamos detenernos a pensar no la reconstitución de la sociedad civil como la fuente

\footnotetext{
${ }^{4}$ Compartimos con Rivera Lugo la perspectiva de que la fuerza material de la normatividad comunitaria "no está en un objetivación o formalización como norma, sino en su capacidad para producir una nueva realidad y constituir la subjetividad correlativa. La norma se materializa por medio de sus efectos y en virtud de la reiteración de las prácticas comunes que le confieren, al fin y a la postre, efectividad." (Rivera, 2016:35)
} 
originaria de lo político - o al menos no sólo —, sino como el resultado de un proceso de enajenación en el que habría que reconstituirse, más bien, la comunidad. Pero no la comunidad política en abstracto, sino la concreta, la que tiene historia.

Lo que le permite a la comunidad serlo son sus instituciones. Sin institucionalidad no puede darse comunidad, en eso radica su factibilidad. La institucionalidad de la justicia, por ejemplo, es paradigmática en el sostenimiento de la comunidad. Sin mecanismos, espacios, maneras para la deliberación en común que se encarguen de resolver los conflictos que nacen al interior, la discordia, la división y el debilitamiento como comunidad serían inevitables. La recomposición y restauración de un vínculo comunitario que ha sido roto - la tranquilidad entre las vecinas y los vecinos, entre las familias - es ejercida desde instituciones que las comunidades se dan: autoridades comunitarias, rondas campesinas, rondas comunitarias, instituciones de justicia que se encargan de sostener la comunidad como Totalidad, como construcción de sentido, de modo de vida, de relaciones ético-político-sagradas entre las personas y el territorio, que no quieren desaparecer.

\section{La esfera formal de legitimidad}

La legitimidad de las instituciones y los consensos están siempre en manos de la propia comunidad $^{5}$. Aunque se podría describir — de manera analítica - , con Dussel, un paso del poder indeterminado de la potentia al poder legislador y constructor de instituciones como potestas, lo importante es que la relación entre ambas conserva una estrechez y un marco ético que cohesiona la institucionalidad a la reproducción de su vida común. Podríamos decir que la fetichización de las instituciones tiene menos fuerza porque la asamblea, como órgano máximo de deliberación y de decisión que las comunidades se dan a sí mismas, tiene mayores diques de contención y mayores alcances de sanción — o al menos cuenta con mejores posibilidades para hacerlo - . En la asamblea "la comunidad manda", las autoridades, los cargos, las vocerías, las representaciones están subordinadas y pueden ser removidas por su decisión. La asamblea se constituye como una forma legítima porque parte del principio de escuchar la palabra de quienes conforman la comunidad, de deliberar y decidir de manera conjunta ${ }^{6}$.

\footnotetext{
${ }^{5}$ Rivera Lugo, en "Derecho de lo común" sostiene: "la soberanía no le pertenece al Derecho, sino al pueblo concreto, según encarnado en lo común. Lo determinante no es hoy, pues, la legalidad sino la legitimidad de cualquier acto. Y la legitimidad se determina crecientemente desde el bien común" (2010:139)

${ }^{6}$ En otro momento nos detendremos a considerar el momento negativo al interior de la propia Totalidad comunitaria y las exterioridades que ella misma genera, que son las que permiten el cuestionamiento de las relaciones de poder y dominación que padecen. El caso de las mujeres, de los niños y las niñas es un ejemplo, pero también el de familias de religiones diversas a la hegemónica en la comunidad.
} 
En las instituciones de justicia, la legitimidad es la que les da el poder de coaccionar y mantener los acuerdos a que se ha llegado de manera colectiva. Sin legitimidad no se aceptan las sanciones, el acuerdo es forzado y no se acata. Hay una especie de sentido común de la justicia que cuando no se ve expresado en la coacción, ésta va perdiendo legitimidad. El exceso en la sanción o la impunidad reducen la factibilidad de la institucionalidad de la justicia. La legitimidad se constituye a partir de una práctica delegada de poder a personas, concejos, que la comunidad concibe como responsables, servidores, pero también en una relación de respeto, muchas veces, como autoridades - sobre todo en los casos en donde lo que podríamos llamar el «campo político» no puede distinguirse analíticamente, desde la modernidad, del «campo sagrado». En todo caso, es la legitimidad y no la fuerza la que les permite su eficacia.

\section{Los principios fundamentales de la vida común}

Cada una de las esferas analíticamente descritas contaría, de manera subyacente, con principios que nos permiten comprender el marco ético-mítico y el horizonte político comunitario. El principio material afirma y desarrolla la vida en comunidad. El principio formal parte de que el consenso de la comunidad, como constructora de Totalidad, es la fuente de su legitimidad. Por último, el principio de factibilidad, que determina su eficacia, es el cumplimiento de lo éticamente posible, y este sentido radica en la capacidad de mantener la reproducción de la vida en común, trabajando por un bienestar compartido y protegido con sus propios mecanismos.

Cuando se afirma y desarrolla la vida en comunidad se constituyen vínculos afectivos, simbólicos, reproductivos que le dan un orden; de ahí deriva su propia racionalidad, la forma que cobra, dependiendo, también, del territorio y de la historia. Cuando la totalidad construida nace del consenso de la voluntad de vivir de la comunidad, la legitimidad se vuelve eficaz.

La normatividad de la política comunitaria está sustentada en criterios que ya no son los originados en la modernidad burguesa - igualdad, libertad y fraternidad —, sino en la reciprocidad, el acuerdo y lo común. No estamos hablando de valores, sino de principios, la reciprocidad no es un valor, en el sentido que no responde únicamente a un juicio ético antropológico, sino a un principio metafísico que expresa la relacionalidad de la vida en comunidad, un mecanismo que permite la articulación de sus miembros, un vínculo que la constituye y da forma. En este caso, no nos interesa abordar lo político desde el individuo racional libre, sino desde el acuerdo que mantiene, cuida, repara, conserva y hace crecer la vida comunitaria. El acuerdo expresa la voluntad de vivir que la comunidad se ha dado a sí misma, es lo que norma y obliga. La corporalidad viviente de la comunidad, como parte del territorio 
que habita, también desborda la noción burguesa de fraternidad, en el sentido de que no se es hermano como individuo, sino como comunitario, miembro de algo más, parte de un todo y, además, no se configura una ruptura con lo que en la Modernidad ha sido llamado «naturaleza» sino, más bien, una conexión profunda con la reproducción, en general, de la vida en el territorio, venciendo, así, rasgos antropocéntricos y objetivantes.

\section{Pretensión política de justicia}

Toda comunidad pretende vivir en tranquilidad, en paz, en equilibrio. El horizonte no es la felicidad individual, sino el bienestar comunitario, en todo caso, el primero estaría subordinado al segundo. Lo justo es la manera en la que la comunidad se asegura a sí misma vivir bien. La pretensión de justicia en las decisiones asamblearias, o en otros espacios de deliberación que se da a sí misma, se basa en la legitimidad que la participación de la comunidad funda.

Pero la pretensión de justicia rebasa el orden de la Totalidad de la comunidad y se expresa en el antagonismo con la Totalidad del Estado-nación moderno, monolítico, capitalista, que busca hacerla desaparecer. En nuestro país, el desmantelamiento de las comunidades desde el siglo XIX por la privatización y desamortización de las tierras, la posterior embestida contra las victorias obtenidas por la Revolución Mexicana y, por último, la aplicación de políticas neoliberales dan cuenta del grado de exterioridad que mantiene en el sistema, y su pretensión de justicia también nace desde ahí. Desde una dimensión crítico-negativa, dicha pretensión de justicia se constituye por la negación de la que es objeto por parte de la Totalidad. El bien común se construye a la par de un momento crítico, es decir, el momento crítico no es posterior, sino que ha estado ahí desde que la comunidad ha debido enfrentarse con modos de producción y de relación social que amenazan con destruirla.

\section{El momento crítico de la comunidad}

La exterioridad de la persona es distinta de la exterioridad de la comunidad. Aunque la persona, para Dussel, siempre muestra el rostro de un pueblo, de una historia, de una lengua, es ella quien expresa a la comunidad. Lo que aquí sostenemos es que, además de la persona como sujeto metafísico y corporalidad viviente, también la comunidad se expresa a sí misma, como un actor constituido por un tipo de vínculo entre las personas, un vínculo que es exterior a la relación social del capital — del cual habría que dar cuenta —, y como corporalidad territorial, que hace manifiesta la materialidad de la vida en común. Con diferentes niveles de exterioridad, derivados de los diferentes grados de participación en la Totalidad, las 
comunidades no sólo expresan subjetividades, sino formas en que la vida humana se organiza para reproducirse.

Estas formas se han mantenido en la historia expresadas en distintas maneras de reproducir la vida en común, enfrentándose a diversas expresiones de la Totalidad. Lo que nos interesa, en el momento crítico, es comprender cómo se constituye la exterioridad de la comunidad en su crítica al orden vigente, a la Totalidad de la Modernidad eurocéntrica, capitalista, colonizadora, racista, patriarcal y heteronormada que la niega, pero de la cual también, en algunos sentidos, participa. Los principios normativos críticos negativos de la comunidad organizada parten del principio material crítico de la defensa, cuidado y reproducción de la vida y los bienes en común que están siendo despojados por los megaproyectos, la urbanización y el despojo de las tierras por las empresas transnacionales. En su dimensión formal de legitimidad, el principio es el consenso de la comunidad como oprimida por un sistema que ha decidido subordinarla - cuando no destruirla - , apropiarse de sus culturas para folklorizarlas, deslegitimar a través de recursos jurídicos sus propias formas de deliberación, decisión e institucionalidad, trabajar en la ciudadanización y modernización de los vínculos que trastocan el tejido comunitario. El principio formal crítico de legitimidad, en este sentido, defiende el proceso a partir del cual se instituyen formas de representación, mecanismos de deliberación y decisión que hacen frente a una Totalidad dispuesta a despojarles su legitimidad a partir de la defensa de un Estado de derecho fetichizado.

Mientras que la separación de la dimensión estatal de la esfera de participación ciudadana es cada vez mayor en la sociedad moderna, en la comunidad, dicha separación encuentra sus diques de contención con el poder que tiene la asamblea para destituir los cargos en caso de que no se cumpla con los objetivos o la ética exigida y para ofrecer espacios de deliberación colectiva en los que la participación directa de las familias y sus miembros orienta la reflexión comunitaria y las decisiones que se derivan de ella. La comunidad establece, entonces, una legitimidad desde su forma constitutiva e institucional hasta sus mecanismos de reproducción, muy distinta de la moderna y que, hoy por hoy, muestra incluso su fuerza efectiva en un mundo en el que la fragmentación y la individuación inconexa reinan como principios hegemónicos de la constitución de lo social.

Una de las críticas más recurrentes a las formas de organización comunitarias es que no cumplen el último principio crítico: el de la factibilidad. Porque se piensa que no están encaminadas de manera clara y directa a la ruptura con la Totalidad para la construcción de una nueva, distinta y más justa. Sin embargo, esto no es precisamente así. Aunque la dimensión 
local en que se juega la construcción comunitaria pareciera ser un límite del horizonte político crítico, lo cierto es que, sobre todo desde el inicio de la década de los noventa, la articulación de los pueblos originarios y comunidades a partir del rechazo al discurso de celebración del quinto centenario de la conquista - como "encuentro de dos mundos" - emprendido por los Estados-nación latinoamericanos, surgió un impulso que les ha movilizado para el fortalecimiento de sus lazos, que buscan no sólo mejorar la propia experiencia interna y compartir las estrategias que se han utilizado, sino constituirse como ejemplos de organización que apuestan por multiplicarse, restándole poder territorial al Estado desde una forma política alterna.

En este sentido, el principio de factibilidad crítico muestra una estrategia encaminada a la expansión territorial que detenga la explotación y el despojo capitalista y al reconocimiento por parte del Estado que lo obligue a respetar la legitimidad de su propio funcionamiento ${ }^{7}$. No es posible reproducir la vida en común en un sistema que privatiza y vuelve mercancía los bienes naturales, no es posible la vida en común en una relación de constante competencia en la que la dominación del Otro se ha naturalizado.

Ahora bien, respecto de la función crítica de la comunidad, partimos de que su exterioridad es profética y mesiánica, es decir, anuncia la caída de los pilares que sostienen la Totalidad que se ha fetichizado y es fuente de construcción de nuevos cimientos emanados de una pretensión de justicia que mantiene, de manera integrada, dimensiones de la existencia que la Totalidad niega: la relación con la tierra, la memoria con el territorio, los bienes naturales como comunes, el vínculo comunitario tejido desde las familias, el trabajo colectivo, la reciprocidad, la autodefensa comunitaria, la institucionalidad y la democracia directas. Lo que la Totalidad moderna liberal capitalista afirma es la tierra como propiedad privada, el desarraigo, el olvido de la historia, la naturaleza como objeto de explotación, lo mismo el ser humano; el individualismo y la competencia, la democracia burguesa fetichizada y el monopolio de la violencia por parte del Estado.

En los casos de mayor exterioridad, sobre todo en el caso de las comunidades originarias, con una fuerte identidad derivada de su quehacer cotidiano, arraigado profundamente a una historia de su ser-estar-hacer comunitario, la reproducción de la vida está

\footnotetext{
${ }^{7}$ Al respecto, Jaime Martínez Luna señala: "Mediante la comunalidad poco a poco vamos resolviendo los problemas locales, pero los que tenemos regionalmente están ahí, en manos de quienes siempre nos han sujetado. Un ejemplo de esto es la explotación de los bosques, donde algunas comunidades han logrado empresas forestales, pero los problemas de mercado, de caminos, etc., debemos enfrentarlos todos. No es posible encarar obstáculos mayores desde la localidad. Tenemos la necesidad de una unión mayor y de una mejor definición del futuro." $(2010: 93)$
} 
engarzada a la comunidad que pertenece a un territorio, constituye valores de uso y por tanto, si se quiere, subjetividades que muestran un Otro, una Otra, no en el rostro de la persona, sino en el sujeto que la propia comunidad construye: yaquis, de la Mixteca, ñu saavi, purépechas, tzeltales, tzotziles, nahuas, ronda campesina, policía comunitaria, "los panchos" — como se conoce a la OPFVII.

Las comunidades concretas mantienen un grado de exterioridad con respecto al Estadonación que las ha negado durante siglos, pero también con la sociedad moderna. En esa negación, su construcción, preservación o reactivación muestran a sujetos políticos comunitarios que constituyen sus propias institucionalidades, sus mecanismos de deliberación y su antagonismo con la voluntad de poder de la institucionalidad moderna del mercado capitalista - tanto el legalizado como el que no - , del individuo moderno que se considera a sí mismo el principio y el fin de la política, que se disgrega en sociedades donde deviene, cuando mucho, en ciudadano; que defiende la propiedad privada como derecho humano, que se vuelve centro y emperador de la naturaleza y, a la vez, dominador del Otro. Aunque, hay que decirlo, toda comunidad participa de algún modo en el sistema: la colonización, el Estado nación y la propia lógica expansiva del capitalismo impiden una exterioridad total y absoluta. Eso que Dussel denomina "trascendentalidad interna" del Otro como Otro, visto desde la dimensión comunitaria, da cuenta de la negatividad interna que actualiza la exigencia de trascender la injusticia de la Totalidad. Aquí radica su potencia crítica como sujeto político antagónico.

Pero es necesario, también, que comprendamos el momento crítico que se da al interior de la comunidad, desde las exterioridades que ella misma genera. En el 2010, cuando las mujeres de la comunidad de la Costa Chica y Montaña de Guerrero se organizaron para constituirse como promotoras de justicia ante la insatisfacción por la resolución de conflictos derivados de la violencia dirigida hacia ellas como mujeres, se enfrentaron a la Totalidad de una cultura patriarcal y machista que impregnaba la institucionalidad comunitaria. Cuando las compañeras que conformaron el Ejército Zapatista de Liberación Nacional lanzan su Ley Revolucionaria de las Mujeres, daban cuenta de una necesidad establecida desde el inicio de la lucha que mostraba las diferentes dimensiones en las que su existencia era negada tanto por la Totalidad comunitaria como por la del Estado-nación neocolonial y capitalista. En estos ejemplos, la exterioridad de la comunidad se expresa en el rostro de una parte ${ }^{8}$ : las mujeres. Y

\footnotetext{
8 "La parte de los sin parte" como la llamó Rancière en El desacuerdo, sujetos de litigio con su propia lógica política que es el resultado del "anudamiento singular del efecto de igualdad con la lógica desigualitaria de los cuerpos sociales que constituye lo propio de la política" (1998:96)
} 
esto ha sido fundamental en la transformación de la justicia comunitaria que ha debido repensarse y reorganizarse para responder a sus demandas.

Las y los jóvenes, por su parte, también han venido interpelando a los poderes gerontocráticos que se han anquilosado en algunas comunidades; cuestionando el conservadurismo tradicional, algunas jerarquías; buscando introducir nuevas instituciones y prácticas con las que se sienten más afines. Los festivales culturales y la radio son un ejemplo en la OPFVII de organización de las y los jóvenes que han venido incorporándose a la vida comunitaria. Sin embargo, no en todos los casos esta integración ha sido efectiva. En las entrevistas y talleres que impartimos con las Rondas Campesinas de Cajamarca, uno de los problemas recurrentes era, precisamente, la poca o nula participación de las y los jóvenes quienes, en gran medida, inmersos en el proceso de mudanza hacia la ciudad, hacia la lógica social de vinculación y al alcance de metas centradas en el aumento de la calidad de vida que individualmente poseen, no parecieran mostrar compromiso ni interés en darle continuidad al proyecto de justicia comunitaria.

La Teología de la Liberación, la doctrina de los Derechos Humanos y el Feminismo han sido elementos que de manera constitutiva - en el caso de la primera - y reconstitutiva han jugado un papel importantísimo en la reivindicación de principios ético-políticos como comunidad, de la participación activa de las mujeres en el consenso y en el proceso de impartición de justicia y en el cuestionamiento constante sobre las sanciones y la manera de reestablecer el bienestar de la vida comunitaria.

La "opción por los pobres" de los catequistas que fundaron las Rondas Campesinas cajamarquinas y su cuestionamiento al modelo de desarrollo capitalista fue fundamental para orientar su horizonte crítico hacia la recomposición del campesinado en una fuerza política que se enfrentara al racismo y al clasismo de la sociedad peruana y del Estado. La incursión de ONG's defensoras de los derechos humanos y el condicionamiento jurídico nacional e internacional que parte del reconocimiento de la justicia comunitaria, siempre y cuando no se vean afectados los derechos fundamentales, han llevado a las comunidades a repensar la manera en la que han venido sancionando y coaccionando, sobre todo, en los casos de castigo físico que, en el caso de las Rondas, llevó, al inicio de su conformación, a dar muerte a grandes abigeos con quienes las comunidades estaban en radical enfrentamiento. $\mathrm{O}$, también en el caso de la OPFVII, constituida por familias nacidas en contexto de marginalidad que suelen estar atravesadas por la violencia, a dar resoluciones deliberadas donde los castigos físicos no son ya la respuesta. En el caso de la CRAC, fundada desde la Teología de la Liberación y el paradigma 
de los derechos humanos, este proceso se dio desde el inicio; sin embargo, hubo que ir trabajando, después, la organización del sector de mujeres que se veían afectadas por el machismo.

Hoy por hoy, por ejemplo, en el caso de las Rondas, jueces de paz o los propios ronderos toman cursos de "igualdad de género", de "empoderamiento de las mujeres campesinas" y aunque, desde lo que alcanzamos a percibir, falta aún mucho trabajo en este sentido, se ha logrado poner el tema sobre la mesa y, poco a poco, las campesinas, históricamente dominadas como pobres y como mujeres, empiezan a participar con más confianza en las asambleas, reuniones, a ocupar cargos importantes dentro de la organización y a recuperar en sus manos la coacción dirigida especialmente hacia ellas.

La interpelación mutua entre derechos humanos-feminismo y las comunidades no ha sido sencilla. Sus presupuestos fundamentales parten de construcciones de sentido muy distintas. El acento que el mundo campesino pone en la familia como la base de sus vínculos comunitarios condiciona, en muchos casos, las perspectivas sobre cómo resolver el problema de la violencia hacia la mujer en el ámbito de lo doméstico. Mientras que las familias, las rondas, las propias víctimas no buscan, mayoritariamente, la emancipación de la mujer del varón que la golpea cuando llega borracho después del trabajo en la chakra, sino la reconciliación, la preservación de la familia, para las organizaciones feministas, estos mecanismos de resolución son insuficientes y no logran vencer el peligro en el que dichas campesinas están inmersas.

Hay una tensión constante en la manera en la que se juega la exterioridad de las mujeres en el mundo de vida comunitario, de manera interna, pero también con actores externos que, desde la presión jurídica o desde la interpelación dialógica, muestran la complejidad de un problema que sigue aún sin resolverse. En otra ocasión hemos mencionado que nos parece que, en este sentido, hay aún tanto qué comprender e investigar que hemos optado por darle la importancia que merece y darle exclusividad en un trabajo posterior. Pero mostramos ya algunos rasgos que nos parecen imprescindibles para pensar, aunque de manera muy incipiente, la construcción de un horizonte crítico comunitario basado en la experiencia de las mujeres como exterioridad de la Totalidad transida de machismo en sus territorios.

Ahora bien, toda experiencia de justicia comunitaria se funda en la crítica al derecho moderno, al que conciben ajeno, invasivo e impositivo y, por tanto, injusto: desde el reconocimiento más simple del derecho como una especie de "justicia para ricos", al que sólo se pueden llevar casos que alcancen o rebasen cierta cantidad económica y no otros de menor 
cuantía - que son los más recurrentes en la comunidad —, pasando por los costos impagables del proceso judicial y la desconfianza en las instituciones del Estado por corruptas o ventajosas al mejor postor, hasta la crítica a las bases sobre las que se cimienta el derecho que, en gran medida, reproduce el horizonte de sentido moderno liberal que tanto las ha debilitado.

La justicia comunitaria, hasta ahora y gracias al Convenio 169 de la OIT, especialmente la de los pueblos originarios, ha logrado descomponer el monolito jurisdiccional del Estado y poner en cuestión el derecho de la nación y la soberanía sobre territorios a los que pertenecen comunidades que apelan a un derecho anterior de posesión o derivado legalmente - por ejemplo, después de la Revolución Mexicana - y, por tanto, a una autonomía que el Estado debe respetar. En este sentido, la crítica al sistema vigente atraviesa por denunciar la no factibilidad ética de un Estado que niegue la constitución política y jurídica de las comunidades, su control territorial y la autogestión de sus bienes naturales.

Aquí el problema se presenta, sobre todo, en el caso de las comunidades urbanas como la OPFVII, porque el aparato jurídico moderno no las reconoce, ya que no son propiamente pueblos originarios, ni se adscriben como tales. Y, entonces, nos obliga a pensar la legitimidad de sus instituciones de justicia en la propia forma comunitaria, como una práctica política subversiva que, sin reivindicar "usos y costumbres", sin partir de una identidad étnica o rural, tiene sus propios principios y su propio horizonte liberador.

La experiencia comunitaria popular en la urbe hace de la dimensión de la justicia una tarea que busca acabar con las desigualdades de clase. Cuando piensan en justicia piensan en salud, educación, cultura, que les son negadas por la dinámica de marginación y explotación capitalista de la ciudad. La pretensión de justicia de estas experiencias participa, además, del horizonte ideológico de la izquierda moderna que ha debido resignificarse desde su contexto y a partir de su propio proyecto. El horizonte del socialismo, del comunismo, los mecanismos de centralismo democrático se articulan con la configuración propiamente comunitaria de la organización en una rica tensión y complejidad que ya ha dado sus frutos y que evidencia su factibilidad.

\section{El momento crítico positivo-creador de la justicia comunitaria}

Cuando una comunidad recupera el territorio que ha perdido a causa de las leyes, cuando la lucha por la tierra en común vence el despojo, cuando se reactivan formas de organización comunitarias por barrios, esquinas, conformando asambleas vecinales o generales, comités, se reinstituye el poder territorial de la comunidad que, aunque no logra destruir la Totalidad de la 
Modernidad capitalista, ni siquiera del capitalismo nacional, rompe su continuidad espacial y de sentido.

Cuando Cherán logró sacar a los talamontes y a todo el corrupto sistema político y judicial municipal, recuperando en manos del pueblo purépecha asentado en el territorio el control y la gestión de los bienes naturales y reorganizando su forma política con base en la memoria de prácticas históricas de deliberación, seguridad y resolución de conflictos, el momento positivo creador que recuperó formas políticas como las asambleas, las comisiones, el concejo, llevó a cabo un trabajo de legitimación doble. Doble porque, por una parte, era necesario obligar al Estado mexicano a que la reconociera y respetara y, por otra, porque también era necesario conformar un consenso explícito que creara y diera el visto bueno de las instituciones por crear.

En el primer sentido, un equipo de abogados y abogadas solidarias emprendieron el proceso legal que culminó con el reconocimiento del Instituto Federal Electoral, cuyos funcionarios se convirtieron en observadores, e incluso escrutadores de los procesos de elección y rotación de cargos. En el segundo, la reactivación de las asambleas por fogatas, por barrios que, cuando el estallido, se habían organizado para resolver la seguridad y la alimentación común, sobre todo, pero que se establecieron como espacios de deliberación política, ha sido una de las creaciones institucionales y núcleos de participación fruto del derrumbamiento de la antigua Totalidad y de la construcción de la nueva.

Lo mismo sucede con los caracoles zapatistas como instituciones de autogobierno que, a partir de la recuperación del territorio y de la reorganización política de las comunidades, ha trabajado durante décadas en la construcción de una justicia que mejore sus condiciones de vida, de salud, de educación y han construido clínicas, escuelas, hospitales, espacios culturales, de deliberación y decisión política y productiva, y han establecido modos de producción, ahorro, intercambio y consumo, recuperando el territorio y los bienes naturales de manos no sólo del Estado, sino del capital.

El nuevo poder constituyente, la nueva legalidad, es una larga transición en este nuevo orden comunitario que tiene una pretensión crítica política de justicia, en el sentido que orienta su praxis liberadora hacia la construcción de un nuevo orden que repara la negación del anterior, instaurando mecanismos de participación sujetos a mayor responsabilidad. La constitución de la comunidad busca, en la propia organización, en el propio ser-hacer-estar comunitario, la consecución de la justicia. La forma comunitaria, en este sentido, no se constituye únicamente 
como una mediación, como podría serlo el partido, el sindicato, sino que es ella misma un fin político.

\section{Conclusiones}

El acercamiento que hemos intentado llevar a cabo entre la Filosofía Política de la Liberación y las experiencias comunitarias como sujetos políticos es incipiente. Apenas muestra algunos elementos que servirían para un análisis ulterior, más profundo y esquemático. Sin embargo, nos parece que hemos avanzado lo suficiente para justificar el marco teórico de la Política de la Liberación como una herramienta comprehensiva de las experiencias comunitarias.

La división entre los momentos de la política de la liberación — arquitectónico positivo, crítico-negativo y crítico positivo - , nos ha sido útil para formular una especie de Totalidad comunitaria que se encuentra en situación de exterioridad frente a una política moderna que ha hegemonizado el sentido de "lo político". Además, nos ayuda a comprender la praxis políticocomunitaria de los pueblos y los barrios que buscan construir una nueva Totalidad y nos permite pensar en el ejercicio de una potestas que es singular, porque es comunitaria.

El momento positivo de la política de la liberación puede ser aplicado para comprender las propias transformaciones de las comunidades campesinas, urbanas, de pueblos originarios, en su victoria frente al Estado y al capital, no en el sentido de que los venza de manera total al nivel nacional siguen siendo hegemónicos y ni qué decir del internacional—, pero sí en el sentido que provoca en ellos una fractura, y no de cualquier tipo, no arbitraria, no nace de fuerzas de la ilegalidad que establecen su propia jurisdicción arrebatándole el monopolio de la violencia al Estado, como lo que vivimos ahora con el narcotráfico, sino, más bien, una fractura que obedece a la práctica de una forma de hacer política antagónica y que se ha configurado desde la experiencia de una exterioridad comunitaria que no renuncia a su derecho a existir.

\section{BIBLIOGRAFÍA}

Dussel, Enrique. (2009) Política de la Liberación. Vol. II. Arquitectónica. Editorial Trotta. Madrid.

Martínez Luna, Jaime. (2010) Eso que llaman comunalidad. Colección diálogos, pueblos originarios de Oaxaca, México.

Rancière, Jacques. (1998) El desacuerdo. Politica y filosofía. Ediciones Nueva Visión. Buenos Aires, Argentina.

Rivera Lugo, Carlos (2016). "La normatividad societal de lo común" en El derecho y el Estado. CLACSO, Argentina. 